\title{
Effects of Programs for Prevention of Early Childhood Caries
}

\author{
A Systematic Review
}

\author{
Jumana B. Ammari ${ }^{a}$ Zaid H. Baqain ${ }^{b}$ Paul F. Ashley ${ }^{c}$

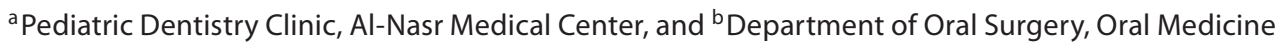 \\ and Periodontology, University of Jordan, Amman, Jordan; ' Department of Pediatric Dentistry, \\ Eastman Dental Institute for Oral Health Care Sciences, University College London, London, UK
}

\section{Key Words}

Dental caries • Young children · Caries prevention • Early

childhood caries

\begin{abstract}
Objective: To determine the most effective intervention program for prevention of early childhood caries. Materials and Methods: All studies published after 1966 were identified by searching electronic databases (Medline, The Cochrane Library, Embase, Dissertation and Serfile databases) and manual searching. Studies were included if they analyzed the effect of an intervention to prevent caries in 0- to 5-year-old children, recorded caries as dmfs, dmft, dfs or dft, and utilized a randomized controlled study design. Results: The initial search produced 916 citations, 19 of which met the inclusion criteria. The quality of the articles was assessed independently by the reviewers based on randomized selection and double blinding. The 7 articles included in the actual review evaluated the effects of dental health education, prenatal fluoride administration, topical fluoride application, preventive dental programs, and use of fluoridated toothpaste. Meta-analysis was not possible because of differences in the types of intervention among the studies. Conclusion: Conclusive evidence regarding the best intervention to prevent early childhood caries could not be drawn
\end{abstract}

due to the flawed design of some papers. However, fluoridebased interventions appear to be effective in young children. More studies are required to determine the best method of delivery.

Copyright $\odot 2007$ S. Karger AG, Basel

\section{Introduction}

Early childhood caries (ECC) is a collective term for the varying patterns of dental decay seen in infants and toddlers. Data concerning the prevalence of this condition are sparse and discrepancies in findings may be due to differences in sampling techniques and study design. However, ECC is believed to represent a major health problem, particularly in low-income populations $[1,2]$. Conventional restorative treatment of the condition is difficult and expensive and may not arrest the actual disease process. In addition, general anesthesia is usually required when treating very young children, adding to morbidity and introducing the risk of mortality. While prevention of ECC is of primary importance for young children, a previous literature review identified few welldesigned studies in the field [3]. In those studies, the positive effects of water fluoridation were thought to have the best scientific evidence. However, since water fluorida-

\section{KARGER \\ Fax +41613061234 \\ E-Mail karger@karger.ch}

www.karger.com
(C) 2007 S. Karger AG, Basel

1011-7571/07/0166-0437\$23.50/0

Accessible online at:

www.karger.com/mpp
Dr. Jumana B. Ammari

Pediatric Dentistry Clinic, Al-Nasr Medical Center

University of Jordan, PO Box 13930

Amman 11942 (Jordan)

Tel. +962 6585 5032,Fax +962 6461 7117,E-Mail jumanaammari@yahoo.co.uk 
tion is not universally administered, the evidence-based effects of other methods of preventing ECC should therefore be explored.

A systematic review is an established method of analyzing existing information, with the aims of extracting results free of bias. Our hypothesis was that a systematic review might be used to analyze studies on the effect of methods other than water fluoridation for ECC prevention and to determine the relative effects of the methods. Randomized controlled trials are considered the most reliable method by which to assess efficacy of treatment. Regardless of whether the results reach statistical significance, the design and conduct of the trial and therefore also of the published report might be of high quality and lead to better and more realistic estimates of the effect of treatment. The aim of this systematic review was to determine the effectiveness of preventive interventions administered by a dentist or another health care professional to a subject or a group at risk of ECC.

\section{Materials and Methods}

\section{Search Strategy for Identification of Studies}

The electronic databases of Medline (from 1966-2003), the Cochrane Controlled Trials, Embase, Dissertation, and Serfile 2000 were searched without language restriction using the following key words: nursing caries, rampant caries, bottle caries, mutans, child, child caries and early childhood caries. The 817 papers identified were searched for further references, yielding another 98 papers. Manual search was carried out in the following journals likely to publish on the prevention of caries in young children: British Dental Journal, Caries Research, Community Dentistry and Oral Epidemiology, International Journal of Pediatric Dentistry, Journal of the American Dental Association, Journal of Dental Research, Journal of Dentistry for Children, Journal of Pediatric Dentistry, and Pediatric Dentistry. The manual search also included abstracts from international proceedings or material published in nonindexed journals. These efforts yielded 1 more paper, for a total 916.

\section{Study Selection}

Studies were excluded if the titles and the abstracts showed that the samples were nonhuman, if the studies were designed as laboratory experiments, if water fluoridation was the main intervention under study or if the samples included children of age 6 years and above at the end of the intervention. The final inclusion criterion was that a randomized controlled study design was performed with $\mathrm{dmfs}$, dmft, deft, dfs or $\mathrm{dft}$ as the final outcome measure.

\section{Effect Modifiers}

The following effect modifiers were identified: level of water fluoridation in the area of the study, use of fluoride supplements, type of tooth brushing technique and supervision, level of socio- economic status of the subjects in the study, participation in any oral hygiene reinforcement program, and subject compliance with active treatment in the study.

Data Extraction and Analyses

Data extraction of descriptive and outcome variables from each of the included studies was carried out independently by the authors, using specially designed forms. Results were compared to check for inconsistencies, and disagreements were resolved through discussion. The effectiveness of the intervention was determined according to the difference in caries prevalence between the test and the control groups according to dmfs, dmft, deft, dfs or dft.

\section{Results}

A total of 733 papers were excluded at the initial stage, leaving 183 papers for possible inclusion. Following review and discussion in situations of disagreement, only 19 papers met the inclusion criteria. Exclusion of the 164 papers was based on failure to describe the actual intervention procedure $(n=63)$, inclusion of children 6 years or older $(\mathrm{n}=86)$, failure to measure changes in $\mathrm{dmfs}$, $\mathrm{dmft}$, deft, dfs or dft $(\mathrm{n}=15)$. The quality of the 19 eligible trials was assessed independently by the reviewers to ascertain randomized assignment of children and blinding of examiners where possible. Only 7 reports satisfied the final inclusion criterion. Of the 12 excluded papers, 11 were not properly randomized and blinded and 1 limited the outcome variable to the presence or absence of white spot lesions. The 7 included clinical trials examined the effect of interventions for the prevention of ECC using dental health education, prenatal fluoride, topical fluoride application, preventive dental programs, and fluoridated toothpaste (table 1). Due to differences in the type of interventions and outcome measures, the use of a meta-analysis for statistical pooling of data was not possible.

\section{Dental Health Education}

Holt et al. [4] examined the effects of dental health education of the mothers of 1,321 children aged 2-12 weeks. Children in the test groups were offered fluoride drops. Only 324 children were left in the study after 5 years, and the attendance rate was different among the groups that were studied. Results showed that the number of caries-free children in group 1 (69\%), whose mothers had been given dental health education through home visits, was significantly greater $(\mathrm{p} \leq 0.05)$ than in group 2 (54\%), whose mothers had been sent dental health education literature by post. However, no significant differ- 
Table 1. Description of intervention and summary of findings

\begin{tabular}{|c|c|c|c|c|c|c|}
\hline Reference & Intervention & $\begin{array}{l}\text { Test group intervention } \\
\text { and number of subjects } \\
\text { at the final examination }\end{array}$ & $\begin{array}{l}\text { Control group intervention } \\
\text { and number of subjects at } \\
\text { the final examination }\end{array}$ & $\begin{array}{l}\text { Summary of findings } \\
\text { (mean deft, dmft, } \\
\mathrm{dft}, \mathrm{dfs} / \mathrm{SD})\end{array}$ & $\begin{array}{l}\text { Significant difference } \\
\text { between test and } \\
\text { control groups }\end{array}$ & $\begin{array}{l}\text { Preventive } \\
\text { fraction } \\
\%\end{array}$ \\
\hline $\begin{array}{l}\text { Holt et al. } \\
{[4]}\end{array}$ & $\begin{array}{l}\text { Dental } \\
\text { health } \\
\text { education }\end{array}$ & $\begin{array}{l}\text { Group 1: given advice } \\
\text { through home visits } \\
(\mathrm{n}=123) \\
\text { Group 2: dental health } \\
\text { education literature } \\
\text { sent by post }(\mathrm{n}=99)\end{array}$ & $\begin{array}{l}\text { Were not contacted during } \\
\text { initial study }(\mathrm{n}=80)\end{array}$ & $\begin{array}{l}\text { Group } 1 \\
\text { (deft 1.12/SD 2.28) } \\
\text { Group } 2 \\
\text { (deft 1.60/SD 2.51) } \\
\text { Control group } \\
\text { (deft 1.73/SD 3.33) }\end{array}$ & $\mathrm{p} \leq 0.05($ group 1$)$ & $\begin{array}{l}35 \text { (group 1) } \\
28 \text { (group 2) }\end{array}$ \\
\hline $\begin{array}{l}\text { Leverett et al. } \\
\text { [5] }\end{array}$ & $\begin{array}{l}\text { Prenatal } \\
\text { fluoride } \\
\text { tablets }\end{array}$ & $\begin{array}{l}\text { 1-mg fluoride tablet } \\
\text { daily }(\mathrm{n}=398)\end{array}$ & Placebo tablet $(n=400)$ & $\begin{array}{l}\text { Treatment group } \\
\text { (dfs 0.45/SD 2.55) } \\
\text { Placebo group } \\
\text { (dfs 0.50/SD 2.83) }\end{array}$ & No & 10 \\
\hline $\begin{array}{l}\text { Linčir and } \\
\text { Rosin-Grget } \\
{[6]}\end{array}$ & $\begin{array}{l}\text { Topical } \\
\text { fluoride }\end{array}$ & $\begin{array}{l}\text { Group 1: topical appli- } \\
\text { cations of conventional } \\
\text { amine fluoride solution } \\
\text { with } 10,000 \text { ppm F } \\
\text { every } 2 \text { months }(\mathrm{n}=55) \\
\text { Group 2: topical amine } \\
\text { fluoride solution with } \\
\text { 5,000 ppm F every } \\
2 \text { months }(\mathrm{n}=53) \\
\text { Group 3: topical amine } \\
\text { fluoride solution with } \\
\text { 5,000 ppm F once } \\
\text { a month }(\mathrm{n}=61)\end{array}$ & Placebo solution $(\mathrm{n}=30)$ & $\begin{array}{l}\text { Group } 1 \\
\text { (dmft 4.0/SD 3.3) } \\
\text { Group } 2 \\
\text { (dmft 4.8/SD 3.6) } \\
\text { Group 3 } \\
\text { (dmft 3.6/SD 2.8) } \\
\text { Control group } \\
\text { (dmft 5.2/SD 3.6) }\end{array}$ & $\begin{array}{l}\mathrm{p} \leq 0.5(\text { group } 1) \\
\mathrm{p} \leq 0.5(\text { group } 3)\end{array}$ & $\begin{array}{l}23 \text { (group 1) } \\
31 \text { (group 2) } \\
46 \text { (group 3) }\end{array}$ \\
\hline $\begin{array}{l}\text { Gomez et al. } \\
\text { [8] }\end{array}$ & PDP & $\begin{array}{l}\text { Children selected to } \\
\text { evaluate the PDP given } \\
\text { to their mothers } \\
(\mathrm{n}=180)\end{array}$ & $\begin{array}{l}\text { Children's mothers were } \\
\text { not involved in any PDP } \\
(\mathrm{n}=180)\end{array}$ & $\begin{array}{l}\text { PDP group } \\
\text { (dft 0.11/SD 0.78) } \\
\text { Control group } \\
\text { (dft } 0.66 / S D ~ 1.55)\end{array}$ & $\mathrm{p} \leq 0.05$ & 83 \\
\hline $\begin{array}{l}\text { Winter et al. } \\
\text { [9] }\end{array}$ & $\begin{array}{l}\text { Fluoridated } \\
\text { toothpaste }\end{array}$ & $\begin{array}{l}550 \mathrm{ppm} \text { F toothpaste } \\
(\mathrm{n}=1,104)\end{array}$ & $\begin{array}{l}1,055 \mathrm{ppm} F \text { toothpaste } \\
(\mathrm{n}=1,073)\end{array}$ & $\begin{array}{l}\text { Test group } \\
(\mathrm{dmft} 1.48) \\
\text { Control group } \\
(\mathrm{dmft} 1.29)\end{array}$ & No & 13 \\
\hline $\begin{array}{l}\text { Davies et al. } \\
{[10]}\end{array}$ & $\begin{array}{l}\text { Fluoridated } \\
\text { toothpaste }\end{array}$ & $\begin{array}{l}\text { Group 1: children re- } \\
\text { ceiving free toothpaste } \\
\text { containing } 1,450 \mathrm{ppm} \mathrm{F} \\
(\mathrm{n}=1,186) \\
\text { Group 2: children re- } \\
\text { ceiving free toothpaste } \\
\text { containing } 440 \text { ppm F } \\
(\mathrm{n}=1,176)\end{array}$ & $\begin{array}{l}\text { Received nothing } \\
(\mathrm{n}=1,369)\end{array}$ & $\begin{array}{l}\text { Group 1 } \\
(\text { dmft 2.15) } \\
\text { Group } 2 \\
(\text { dmft 2.49) } \\
\text { Control group } \\
(\text { dmft 2.57) }\end{array}$ & $\mathrm{p} \leq 0.05($ group 1$)$ & $\begin{array}{r}16 \text { (group 1) } \\
3 \text { (group 2) }\end{array}$ \\
\hline $\begin{array}{l}\text { You et al. } \\
\text { [11] }\end{array}$ & $\begin{array}{l}\text { Fluoridated } \\
\text { toothpaste }\end{array}$ & $\begin{array}{l}\text { Children receiving } \\
\text { toothpaste containing } \\
1,100 \mathrm{ppm} \mathrm{F} \text { and oral } \\
\text { health program }(\mathrm{n}=386)\end{array}$ & $\begin{array}{l}\text { Placebo toothpaste, } \\
0 \text { ppm F }(\mathrm{n}=445)\end{array}$ & $\begin{array}{l}\text { Test group } \\
\text { (dmfs 3.81/SD 0.26) } \\
\text { Control group } \\
\text { (dmfs 4.81/SD 0.24) }\end{array}$ & $\mathrm{p} \leq 0.05$ & 21 \\
\hline
\end{tabular}

$\mathrm{dmfs}=$ Decayed, missing, filled surfaces; $\mathrm{dmft}=$ decayed, missing, filled teeth; deft = decayed, extracted, filled teeth; dft = decayed, filled teeth; $\mathrm{dfs}=$ decayed, filled surface; $\mathrm{PDP}=$ preventive dental program. Preventive fraction is a measure of how much caries is prevented by a particular intervention, calculated by taking the difference between mean $\mathrm{dmfs}$ in the control and test groups and dividing it by the mean $\mathrm{dmfs}$ of the control group, expressing the answer as a percentage. 
ence $(p>0.05)$ was detected between the children in group 2 and those in the control group (58\%). The authors concluded that trends for better dental health were seen among children whose mothers had been given dental health education at home.

\section{Prenatal Fluoride}

Leverett et al. [5] evaluated the effect of prenatal fluoride on ECC in 1,400 pregnant women in the USA. During the last 6 months of pregnancy the treatment group received a 1-mg fluoride tablet daily while the control group received a placebo. The children in the two groups were compared, examining all from birth to 5 years of age. Regardless of the group assignment, all mothers were encouraged to give their offspring postnatal dietary fluoride supplements. These were administered in the form of fluoride drops from birth until the 2nd birthday. The dropout rate in both groups (32\%) was similar at the end of the study. Caries prevalence was low in both groups, $8 \%$ in the treatment group and $9 \%$ in the placebo group ( $p>0.05)$. The findings fail to support the hypothesis that prenatal fluoride has a caries-preventive effect.

\section{Topical Fluoride Application}

Attempting to evaluate the effect of topical fluoride application, Linčir and Rosin-Grget [6] conducted a 2year study in a kindergarten in Croatia of 3- to 4-year-old children who had not been included in any preventive dental program prior to the study. The protocol involved application of different topical fluoride concentrations at two different frequencies. The study was conducted in an area where the fluoride content in the drinking water was $0.1 \mathrm{ppm}$ F. The overall dropout rate was $15 \%$. The group receiving topical amine fluoride solution with $5,000 \mathrm{ppm}$ $\mathrm{F}$ once a month experienced $31 \%$ less new decay $(34 \%$ fewer new dmfs), as calculated according to Rugg-Gunn et al. [7], than the control group, and the group receiving topical amine fluoride solution with $10,000 \mathrm{ppm} F$ every 2 months experienced $23 \%$ less new decay (31\% fewer new $\mathrm{dmfs}$ ) than the control group. They concluded that increased frequency of application of a low-fluoride topical solution (10 times a year) may provide caries protection in preschool children with relatively high caries activity.

\section{Preventive Dental Programs}

Gomez and Weber [8] conducted a 4-year study looking at the effectiveness of a mother and child preventive dental program. The program consisted of three parts: the first part included examination of dental disease, oral hygiene, and dietary habits; the second tested the effect of education on oral hygiene and dietary habits of the pregnant mothers; the third involved the effect of preventive or restorative treatment of oral disease among the mothers. Nine hundred and thirty pregnant women in their fourth month of pregnancy were admitted to the preventive dental program. After 4 years, 241 women had complied with the requirements and were put on a list of mother-child pairs. Children aged 1-3.5 years were assigned to two groups comparable in age, socioeconomic status and water fluoridation (1.0 ppm). Ninety-seven percent of the children in the preventive dental program group were caries-free compared to $77 \%$ of the children in the control group $(p<0.05)$. The conclusion was that the preventive dental program for pregnant mothers was effective in inhibiting caries in preschool children.

\section{Fluoridated Toothpaste}

The three final trials tested the preventive effect on caries of fluoridated toothpaste. Winter et al. [9] carried out a 3-year study in the UK comparing two fluoride toothpastes in 2-year-old children (control group 1,055 ppm F, test group 550 ppm F). Junior-size multitufted toothbrushes were distributed to the children who participated in the trial at the beginning of the study as well as at 3-month follow-up intervals for a period of 3 years. The dropout rate was about $28 \%$. At the end of the study, the prevalence of caries-free children was higher in the control group (63\%) than in the test group (58\%), and the difference was statistically significant $(\mathrm{p}<0.05)$. However, the authors reported similar mean $\mathrm{dmft}$ between the children in the two groups. The study concluded that the low-fluoride toothpaste possessed a similar anticaries activity to the control paste and could therefore be recommended for use in young children.

Davies et al. [10] assessed the effect of providing free fluoridated toothpaste on caries reduction for children aged 5-6 years and mailed dental health information to parents, recommending the use of a pea-sized amount of toothpaste for twice-daily brushing from the age of 12 months and onwards. A total of 7,422 children living in high caries risk areas in the northwest of England (according to the biennial national survey coordinated by the British Association for the Study of Community Dentistry) were randomly allocated to three groups. One group received free toothpaste containing $1,450 \mathrm{ppm} \mathrm{F}$, another received free toothpaste containing $440 \mathrm{ppm} \mathrm{F}$, and a third (control) did not receive any toothpaste. There was a total dropout rate of $50 \%$, with almost equal rates in the three groups. Results showed that the difference was statistically significant between the $1,450 \mathrm{ppm} F$ and 
the control group $(\mathrm{p}<0.05)$, but not between the $440 \mathrm{ppm}$ $F$ group and the control group. The authors concluded that the distribution of free toothpaste containing 1,450 ppm $\mathrm{F}$ provides a significant clinical benefit for children in high caries risk areas.

You et al. [11] examined the caries-preventive effect of $1,100 \mathrm{ppm} F$ toothpaste used in preschool children. A total of 1,334 3-year-old children in China were randomly assigned to two groups. Children in the treatment group received an oral health program designed to educate both teacher and children about the importance of oral hygiene, using videotapes and audiotapes supplemented with pictures. The children brushed for $60 \mathrm{~s}$ twice daily with a pea-sized dose of 1,100 ppm F toothpaste under the supervision of a classroom teacher. Children in the control group received placebo toothpaste ( $0 \mathrm{ppm} \mathrm{F}$ ), did not receive the school oral health education program, and did not participate in the supervised classroom brushing. The dropout rate was $31.3 \%$. Results showed a significant difference $(20.7 \%, \mathrm{p} \leq 0.05)$ between the treatment and the control group, demonstrating that fluoride in conjunction with increased dental awareness can result in important caries reduction in preschool children.

\section{Discussion}

In this study, 7 randomized controlled trials of sufficient quality emerged from a systematic review of interventions to prevent caries in young children. Due to the differences in the type of interventions, a meta-analysis of the 7 trials was not possible. Similarly, differences in the level of fluoridated toothpaste precluded direct comparison of the three toothpaste studies included. The quality of all eligible trials for this systematic review was assessed based on concealment of assignment to groups and blinding.

The selection of papers of high quality is important since the quality of a trial gives an estimate of the likelihood that the results are unbiased. Of particular importance in this respect is randomization and blinding. However, the accepted downside of restricted selection criteria is inclusion of few studies, resulting in conclusions based on a small number of subjects. Several papers initially identified had to be excluded due to a lack of proper randomization of group assignment. Papers were also excluded from the review because of inappropriate blinding. Only 3 of the included studies were double-blinded [5, 6, 9]. In the first [4] and the fourth [8] study, only the observer was blinded to the intervention, since the mothers were aware that they were actually receiving an intervention. In the sixth study [10], the subjects and their families were aware of the type of toothpaste they were using. These deviations from the inclusion criteria were considered appropriate since the purpose of the study was to evaluate the effectiveness of the program rather than the efficacy of the products per se, necessitating a design that differed from that of a conventional clinical trial. Several of the excluded studies suffered from poor quality of reporting, with missing information on important issues such as method of randomization, dropout figures, estimation of sample size, and measures of outcome variability. Some of these data were even missing from the included studies, such as the baseline level of caries and the standard deviation in Winter et al. [9]. Full reporting of data is important to ensure that results are easily understandable by all professionals and that meta-analysis can be carried out, if appropriate. Clear guidelines for the presentation of randomized controlled trials were laid down in 1995 [12], specifying the inclusion of 5 new subheadings in the text, 3 of which should be within the methods section ('protocol', 'assignment', and 'blinding') and 2 in the results section ('participant flow and follow-up', and 'analysis'). It is recommended that these guidelines be taken into consideration when planning further research, as they provide readers with consistency from report to report, ultimately leading to a more comprehensive reporting of randomized controlled trials. Attempts should be made to contact authors for further information where data are unclear or missing. However, the authors of this article met limited success following this practice, which was discontinued due to time constraints.

It may be argued that the criteria for selection in this systematic review were too rigid. However, trials with inadequate or unclear concealment of group assignment and trials without appropriate blinding tend to overestimate beneficial effects [13]. Since exclusion of such trials tends to conclude with a less beneficial effect of the treatment, the methodological quality would have a substantial impact on the conclusions of systematic reviews [13]. The effect of fluoride varnish could not be analyzed, since the identified studies failed to meet the criteria of this study. Furthermore, one study was excluded [14] because the outcome variable was presence or absence of white spot lesions, which may not be considered a form of ECC and therefore could not be compared to standard outcomes such as dmfs, dmft, deft, dfs or dft.

One important inference of this systematic review may be that postnatal application of fluoride seems to have a beneficial effect. The use of fluoride toothpastes 
appears particularly promising, as this is a relatively simple way of delivering fluoride in a targeted manner and may be more socially acceptable than water fluoridation. It may be of interest that in two of the included studies, that by Davies et al. [10] and that by You et al. [11], this was only achieved by the use of 'adult' fluoridated toothpaste $(>1,000 \mathrm{ppm} F)$. This finding is supported by a recent systematic review on the effectiveness of low- and high-fluoride toothpaste [15], showing that $250 \mathrm{ppm} \mathrm{F}$ dentifrice is less effective for caries prevention in permanent dentition than dentifrice containing $1,000 \mathrm{ppm} F$ or more. However, it is well established that the use of 'adult' fluoridated toothpastes may be associated with an increased risk of fluorosis.

Our systematic review does not allow additional inferences. The results of the included trials were often difficult to interpret because of effect modifiers (factors other than the interventions studied that might increase or decrease a patient's likelihood of developing caries), such as administration of fluoride tablets to all the participants in two studies regardless of other types of interventions $[5,6]$, offering fluoride drops to the children of participating mothers in the included trial on the effect of dental health education [4], the presence of water fluoridation included in the trial on the effect of preventive dentistry programs [8], and the use of children's supervised brushing in the only treatment group in the included study on the effect of fluoridated toothpaste [11]. In addition, several of the trials suffered from high dropout rates $[5,8,9]$, introducing the risk of attrition bias. Since this systematic review was unable to provide conclusive evidence regarding the relative effects of interventions other than water fluoridation for the prevention of caries in young children, an important conclusion is that more research is needed in this area. Since clinical trials are expensive to run and difficult to undertake, multicenter studies may be the best solution to insure appropriate sample sizes.

\section{Conclusion}

This systematic review shows that there is no definitive evidence regarding the effect of a specific intervention on a specific cause or pattern of ECC. Whereas fluoride-based interventions appear to be effective in protecting deciduous teeth, more carefully designed studies with adequate power and sufficiently long follow-up are required.

\section{Acknowledgement}

The authors would like to thank Dr. Ruth Holt for her valuable advice.

\section{References}

1 Tinanoff N: Introduction to the early childhood caries conference: initial description and current understanding. Community Dent Oral Epidemiol 1998;26(suppl 1):5-7.

$\checkmark 2$ Milnes AR, Rubin CW, Karpa M, Tate R: A retrospective analysis of the costs associated with the treatment of nursing caries in a remote Canadian aboriginal preschool population. Community Dent Oral Epidemiol 1993;21:253-260.

3 Ismail AI: Prevention of early childhood caries. Community Dent Oral Epidemiol 1998; 26(suppl 1):49-61.

-4 Holt RD, Winter GB, Fox B: Effects of dental health education for mothers with young children in London. Community Dent Oral Epidemiol 1985;13:148-151.

$\checkmark 5$ Leverett DH, Adair SM, Vaughan BW, Proskin HM, Moss ME: Randomized clinical trial of the effect of prenatal fluoride supplements in preventing dental caries. Caries Res 1997;31:174-179.

-6 Linčir I, Rosin-Grget K: Caries-preventive effect of two different topical fluoride con- centrations with two different frequencies of application in preschool children. Caries Res 1993;27:484-487.

7 Rugg-Gunn AJ, Holloway PJ, Davies TG: Caries prevention by daily fluoride mouthrinsing. Report of a three-year clinical trial. Br Dent J 1973;135:353-360.

8 Gomez SS, Weber AA: Effectiveness of a caries preventive program in pregnant women and new mothers on their offspring. Int J Paediatr Dent 2001;11:117-122.

-9 Winter GB, Holt RD, Williams BF: Clinical trial of a low-fluoride toothpaste for young children. Int Dent J 1989;39:227-235.

10 Davies GM, Worthington HV, Ellwood RP, Bentley EM, Blinkhorn AS, Taylor GO, Davies RM: A randomized controlled trial of the effectiveness of providing free fluoride toothpaste from the age of 12 months on reducing caries in 5-6 year old children. Community Dent Health 2002;19:131-136.

11 You B, Jian WW, Sheng RW, Jun Q, Wa WC, Bartizek RD, Biesbrock AR: Caries prevention in Chinese children with sodium fluo- ride dentifrice delivered through a kindergarten-based oral health program in China. J Clin Dent 2002;13:179-184.

12 Moher D, Schulz KF, Altman DG: Improving the quality of reporting of randomized controlled trials. http://www.consort-statement. org/statement.html.

13 Egger M, Juni P, Bartlett C, Holenstien F, Sterne J: How important are comprehensive literature searches and the assessment of trial quality in systematic reviews? Empirical study. Health Technol Assess 2003;7:1-76.

14 Lopez L, Berkowitz R, Zlotnik H, Moss M, Weinstein P: Topical antimicrobial therapy in the prevention of early childhood caries. Pediatr Dent 1999;21:9-11.

15 Ammari AB, Bloch-Zupan A, Ashley PF: Systematic review of studies comparing the anti-caries efficacy of children's toothpaste containing $600 \mathrm{ppm}$ of fluoride or less with high fluoride toothpastes of $1,000 \mathrm{ppm}$ or above. Caries Res 2003;37:85-92. 